\title{
THE IMPACT OF PRIMARY POSTPARTUM HEMORRHAGE IN "NEAR- MISS" MORBIDITY AND MORTALITY IN A TERTIARY CARE HOSPITAL IN NORTH INDIA
}

VIROCHANA KAUL*, RASHMI BAGGA, VANITA JAIN, SARALA GOPALAN

\section{ABSTRACT}

AIM: To assess risk factors, mortality and "near-miss" morbidity in early PPH. SETTING AND DESIGN: Retrospective analysis of 178 women with early PPH (within $24 \mathrm{~h}$ of delivery) over 4 consecutive years in a tertiary care hospital in North India. MATERIALS AND METHODS: All case sheets of patients identified by labor record registers as having early $P P H$ were reviewed by the same person to identify the actual impact of condition. The data was analyzed by chi-square analysis. RESULT: Early PPH (loss of blood that caused significant alteration in maternal condition or blood loss $>500$ in vaginal deliveries or $>1000 \mathrm{cc}$ in cesarean section) was recorded in 178; 90 delivered in hospital (Group-A) and 88 referred after delivery (Group-B) from various peripheral centers, i.e., maternity hospitals, nursing homes, district and community health centers. The maternal mortality ratio during this period was 1049/ 100,000 (139 deaths/13248 live births; direct maternal deaths = 94). Early PPH accounted for $11 / 94$ direct maternal deaths (11.7\%). Of these 11 deaths, 3 were in group $A$ and 8 in group B. "Near-miss" morbidity was higher than mortality (Total 19/178; 5/90 in Group-A and 14/88 in Group-B). Delayed referral and lack of active $3^{\text {rd }}$ stage management in Group-B were responsible for most of the adverse events. CONCLUSION: Both "near-miss" morbidity and mortality in early PPH reflect the level of obstetric care in the developing world. These need to be reduced by strengthening peripheral delivery facilities, active $3^{\text {rd }}$ stage management and early referral.

Key words: Maternal mortality; "near-miss" morbidity; primary postpartum hemorrhage.

Department of Obstetrics and Gynaecology, Postgraduate Institute of Medical Education and Research, Sector-12, Chandigarh, *Manipal Medical College, Manipal, Karnataka, India

\section{Correspondence}

Rashmi Bagga, Department of Obstetrics and Gynaecology, Postgraduate Institute of Medical Education and Research,

Sector 12, Chandigarh - 160012 , India.
E-mail: rashmibagga@gmail.com
Postpartum hemorrhage (PPH) has been a nightmare for obstetricians since centuries. Currently in developed countries, embolism is the leading cause of maternal mortality, following improvement in the prevention and the treatment of the three traditional horsemen (hemorrhage, infection and hypertension). ${ }^{[1]}$ However, in developing countries, $\mathrm{PPH}$ continues to be a leading cause accounting for $25-43 \%$ of maternal deaths. ${ }^{[2,3]}$ An early observational study reported that blood loss more than $500 \mathrm{ml}$ occurs in $40 \%$ women after vaginal delivery and more than $1000 \mathrm{ml}$ in $30 \%$ women after an elective repeat cesarean section. ${ }^{[4]}$ The WHO technical working group, 1990 , defined PPH as bleeding in excess of $500 \mathrm{ml}$ in the first $24 \mathrm{~h}$ after delivery. ${ }^{[5]} \mathrm{PPH}$ is a frequent complication of delivery and its incidence is commonly reported as $2-4 \%$ after vaginal delivery and $6 \%$ after cesarean section with uterine atony being the cause in about $50 \%$ cases. ${ }^{[6]}$ Many studies have suggested this to be an underestimation of normal loss and some suggest cutoff for clinically significant PPH should now be revised to $1000 \mathrm{ml}^{\left[{ }^{[7]}\right.}$ The aim of this study was to identify the causes for early PPH and to assess the extent of morbidity, especially the "near-miss" cases as well as mortality associated with it. "Near-miss" morbidity is considered to be an underestimated but more sensitive indicator of maternal health than mortality.

\section{MATERIALS AND METHODS}

This study was carried out in the Postgraduate Institute of Medical Education and Research, Chandigarh, a tertiary care hospital in North India. A retrospective analysis of all women with early $\mathrm{PPH}$ (within the first $24 \mathrm{~h}$ of delivery) during a period of 4 consecutive years (2000 to 2003) was done by the same person. $\mathrm{PPH}$ in the institute was measured both objectively and subjectively, i.e., any amount of blood loss following birth that adversely affected the mother as well as loss $>500 \mathrm{ml}$ in vaginal and $>1000 \mathrm{ml}$ during cesarean section (estimated from the use of sponges and blood in suction by the attending staff). The criteria for diagnosis for the deliveries occurring outside the institute was not clear but since they were referred with the diagnosis of PPH from outside and mos were in a moribund state, no exact definition was sought from them. Such women were identified from the labor record registers and then all case sheets were reviewed and demographic variables of age, parity, period of gestation, mode of delivery were noted. The cause of PPH and medical or surgical interventions were analyzed. Morbidity assessment was done and "near-miss" morbidity was identified using the scoring system outlined by Geller et al.[8,9] "Nearmiss" morbidity is considered a sensitive indicator of assessment. ${ }^{[10]}$

In this system, five clinical factors - organ failure ( $\geq 1$ system), extended intubation ( $\geq$ $12 \mathrm{~h})$, ICU admission, surgical intervention and transfusion ( $\geq 3$ units) are - grouped into a scoring system. The total score is calculated as the weighted sum of the clinical factors present for each woman. This scoring system has a specificity of $93.9 \%$. A total score was calculated as the weighted sum of clinical factors present for each woman, with a score of $\geq 8$ considered as "near-miss" morbidity. In our hospital, active managemen of $3^{\text {rd }}$ stage in the form of intramuscula ergometrine at delivery of the anterior shoulder or 10-20 units oxytocin infusion in $500 \mathrm{ml}$ normal saline and controlled cord traction is practiced routinely. A note was made of similar practices done outside. 


\section{RESULTS}

During the study period, a total of 13,907 women delivered in our hospital. Of these, 90 had early PPH (incidence $0.6 \%$ ). In addition, 88 women were referred from peripheral health centers with early PPH. Thus we had a total of 178 women with primary $\mathrm{PPH}$ for analysis. The median age was 23 years and the mean gestation at delivery was 37.3 weeks. Nearly half of the women $(47.1 \%)$ were primiparous and pregnancy had been supervised in only about one-fourth (26.4\%). The onset of labor was spontaneous in 50.6\% and $65.7 \%$ delivered vaginally. For the purpose of analysis, we divided the women with PPH into two groups - Group A (women who delivered in this hospital, $n=90$ ) and Group B (women referred after having delivered elsewhere $n=88$ ).

Table 1 shows the labor characteristics and

causes of PPH in the two groups. In our hospital, active management of $3^{\text {rd }}$ stage is practiced routinely. However, routine active management of $3^{\text {rd }}$ stage, though recommended by the $\mathrm{WHO}$, was practiced in only $36.4 \%$ of the women in group B. This fact may be responsible for the finding that though uterine atony emerged as the leading cause of PPH in both groups, it was significantly higher (almost double) in those who delivered elsewhere and were referred to this hospital with $\mathrm{PPH}$. The atonicity in group $B$ was also contributed to by retained placental tissue and uterine inversion, thus highlighting the need for proper delivery techniques. Among deliveries in our hospital, $20 \%$ of cases of PPH were due to abruptio placentae or placenta accreta, causes that cannot be prevented. In majority of the women $(87.9 \%)$, the excessive bleeding occurred within $6 \mathrm{~h}$ of delivery. However, majority $(61.3 \%)$ of the women who delivered

Table 1: Labor characteristics and causes of early PPH

\begin{tabular}{|c|c|c|c|c|}
\hline & \multicolumn{2}{|c|}{ Early postpartum hemorrhage $(n=178)$} & \multirow[b]{2}{*}{$x^{2}$} & \multirow[b]{2}{*}{$P$ value } \\
\hline & $A(n=90)$ & $B(n=88)$ & & \\
\hline \multirow{2}{*}{\multicolumn{5}{|c|}{$\begin{array}{l}\text { Active management of } 3^{\text {rd }} \text { stage } \\
\text { Timing of presentation (group A) }\end{array}$}} \\
\hline & & & & \\
\hline - Within 6 hrs & $79(87.9)$ & & & \\
\hline - 6-12 hrs & $4(4.4)$ & & & \\
\hline - $12-24 \mathrm{hrs}$ & $7(7.7)$ & & & \\
\hline \multicolumn{5}{|l|}{ Timing of referral (group B) } \\
\hline - Within 6 hrs & & $34(38.7)$ & & \\
\hline $\begin{array}{l}\text { - } 6-12 \mathrm{hrs} \\
\bullet 12-24 \mathrm{hrs}\end{array}$ & & $\begin{aligned} 48(54.5) \\
6(68)\end{aligned}$ & & \\
\hline $\begin{array}{l}\bullet 12-24 \text { hrs } \\
\text { Uterine atony }\end{array}$ & $43(47.7)$ & $\begin{array}{l}67(8.8) \\
77.5)\end{array}$ & 22.4 & $<0.05(\mathrm{~S})$ \\
\hline Uterine inversion & $1(1.1)$ & $8(9.1)$ & 3.87 & $<0.05$ (S) \\
\hline Retained placenta & $2(2.2)$ & $26(29.5)$ & 16.74 & $<0.05$ (S) \\
\hline Traumatic & $19(21.1)$ & $12(13.6)$ & 0.83 & $>0.1$ (NS) \\
\hline - Lower genital tract & $16(17.7)$ & $4(4.5)$ & 5.14 & $<0.1$ (S) \\
\hline - Uterine rupture & $3(3.3)$ & $8(9.1)$ & 1.41 & $>0.1$ (NS) \\
\hline Combined & $10(11.1)$ & $10(11.3)$ & 0.88 & $>0.1$ (NS) \\
\hline Abnormal placentation & $28(31.1)$ & $19(21.5)$ & 0.04 & $>0.1$ (NS) \\
\hline - Placenta praevia & $10(11.1)$ & $10(11.3)$ & 0.88 & $>0.1$ (NS) \\
\hline - Abruptio placentae & $12(13.3)$ & $8(9.1)$ & 0.32 & $>0.1$ (NS) \\
\hline - Placenta accreta & $6(6.6)$ & $1(1.13)$ & 2.07 & $>0.1$ (NS) \\
\hline Coagulation defects & $4(4.4)$ & $4(4.5)$ & 0.11 & $>0.1$ (NS) \\
\hline
\end{tabular}

Figures in parentheses are percentage elsewhere reached our hospital after $6 \mathrm{~h}$, thus losing precious time.

The frequency and severity of complications were more in group B. Amongst injuries, lower genital tract trauma was significantly more in hospital deliveries, but uterine rupture was more in the referred group (although not statistically significant).

Table 2 shows the overall morbidity and mortality data. There were a total of 11 deaths among 178 women with $\mathrm{PPH}$ (mortality rate $6.1 \%$ ). During the study period, there were 14,244 total births and 13,248 live births at our hospital (Annual statistics, Department of Obstetrics and Gynaecology, Postgraduate Institute of Medical Education and Research, Chandigarh, India). The maternal mortality ratio during this period was 1049/100,000 (139 maternal deaths/13,248 live births). Of these, 94 were direct maternal deaths $(67.6 \%)$. Early or primary $\mathrm{PPH}$ accounted for $11.7 \%$ of the direct deaths (11/ 94). Between the two groups, though there were more deaths among the women delivered elsewhere and referred with $\mathrm{PPH}$, this difference did not achieve statistical significance. Thus, though the overall

Table 2: Mortality and Morbidity due to PPH

\begin{tabular}{lcccc}
\hline & Group $A(n=90)$ & Group B $(n=88)$ & $X$ & $P$ value \\
\hline Mortality & $3(3.3)$ & $8(9.1)$ & 2.74 & $>0.1$ (NS) \\
- Rupture uterus & $2(2.2)$ & $1(1.1)$ & & \\
- Coagulopathy & $1(1.1)$ & $1(1.1)$ & & \\
- Uterine inversion & & $6(6.8)$ & & \\
- Organ system failure & & $14(15.9)$ & 5.05 & $<0.05$ (S) \\
Near-miss' morbidity & $5(5.5)$ & $48(54.5)$ & 31.27 & $<0.001$ (S) \\
- Organ failure & $7(7.7)$ & $16(18.2)$ & 5.45 & $<0.02(\mathrm{~S})$ \\
- ICU admission & $6(6.6)$ & $16(18.2)$ & 5.45 & $<0.02$ \\
- Extended intubation & $6(6.6)$ & $61(69.3)$ & 36.74 & $<0.001$ (S) \\
- Transfusion $>3$ units & $21(23.3)$ & $72(81.8)$ & 12.30 & $<0.001$ (S) \\
- Surgical intervention & $52(57.7)$ & & & \\
\hline
\end{tabular}

mortality was not significantly different majority of the deaths in Group B were associated with multiple organ failure, which is an indirect indicator of delay in initiation of treatment.

An attempt to analyze "near-miss" morbidity (cases that could easily have progressed to mortality) was made in order to identify factors that can trigger events that may ultimately lead to maternal mortality. Nineteen women $(10.7 \%)$ suffered "near-miss" morbidity. The causes for "near-miss" morbidity in women delivered in our hospital (Group A) were placenta accreta (3 cases), followed by uterine rupture and abruptio in 1 case each. Amongst the referred cases (Group B), placenta previa, uterine rupture atony and placenta accreta accounted for 6 4,3 and 1 cases respectively. Amongst the 19 women, the major group comprised of referral patients. Delayed referral (transfer time $>6 \mathrm{~h}$ after delivery) was observed in Group B in 54/88 (61.3\%) and all 14 women who had "near-miss" morbidity had reached our hospital $>6 \mathrm{~h}$ after delivery.

Although a score of $\geq 8$ was taken as cutoff for near-miss morbidity evaluation, yet as 
shown in Table 2, individual factors assessed were high and their impact on quality of life cannot be understated. Again, a comparison between the two groups revealed higher rate of complications in the referred group with organ failure sevenfold more, while ICU admission, extended intubations and $\geq 3$ units transfusion rate were threefold more and surgical intervention 1.2-fold higher than in those who delivered in our hospital.

In Table 3, the details of the morbidity in all cases reveal a significantly high morbidity in all these women and again a greater number amongst the outside deliveries, with the cardiac causes (hypotension) mainly contributing to the organ system failure. Major surgical interventions including hysterectomy, bilateral internal iliac ligation and embolization of uterine artery were required in more cases in Group B, signifying the severity of complications in this group.

\section{DISCUSSION}

Maternal mortality has been used traditionally as a measure of quality of health care. However, recently maternal morbidity, especially "near miss" morbidity, is being taken into account to assess the burden of

Table 3: Morbidity factors

\begin{tabular}{lcc}
\hline & Group $A(n=90)$ & Group $B(n=88)$ \\
\hline Organ system failure & & \\
Cardiac (arrest, failure, hypotension) & $7(7.7)$ & $48(54.5)$ \\
Pulmonary (intubation, arrest, ARDS) & $2(2.2)$ & $6(6.8)$ \\
Haematccoagulation (DIC, platelets < 50,000) & $7(7.7)$ & $10(11.3)$ \\
CNS (coma, ICH) & $6(6.6)$ & $7(7.9)$ \\
Renal (ARF, dialysis) & $4(4.4)$ & $2(2.2)$ \\
Surgical intervention (excluding caesarean and episiotomy) & $52(57.7)$ & $72(81.8)$ \\
Hysterectomy & $13(14.4)$ & $21(23.9)$ \\
Bilateral internal iliac artery ligation & $2(2.2)$ & $6(6.8)$ \\
Embolization of uterine artery & $1(1.1)$ & $4(4.5)$ \\
Reposition of uterus & $1(1.1)$ & $8(9.1)$ \\
\hline
\end{tabular}

Figures in parentheses are percentage disease. Apparently, two-thirds of obstetric morbidity is related to hemorrhage. ${ }^{[11]}$ It has been estimated that PPH increases the risk of morbidity 50 times and has nearly 5 times higher morbidity than mortality. ${ }^{[12]}$ This study attempts to analyze the data of women who had early PPH over a 4-year period - in order to identify the causes, mortality and "nearmiss" morbidity associated with it as well as the risk factors that contribute to the adverse outcomes.

An assessment of the causes of early $\mathrm{PPH}$ revealed that the incidence of uterine atony, retained placenta and uterine inversion is significantly less among women delivered in our hospital as compared to women referred with $\mathrm{PPH}$ after having delivered elsewhere. The regular use of active management in the $3^{\text {rd }}$ stage, as well as prompt recognition of complications with institution of appropriate management, emerges as the obvious reason. The main causes of $\mathrm{PPH}$ among the hospital delivery group (Group A) were abruptio placentae and placenta accreta; none of which are preventable and all of which are nearly always associated with significant morbidity despite all attempts to prevent $\mathrm{PPH} .{ }^{[13]}$ The time of presentation of $\mathrm{PPH}$ in Group A in majority (87\%) of the cases was within $6 \mathrm{~h}$ of delivery, highlighting the need for continuous vigilance postpartum and prompt action in case of problems.

The mortality in Group B was more than in Group A despite the fact that our hospital caters to a high-risk population (eight versus three). However, the difference in the overall mortality between the hospital deliveries and those delivered elsewhere was not statistically significant. This implies that PPH persists as a cause of mortality despite providing adequate intranatal care..$^{[13-15]}$ Evaluation of the causes of mortality shows that multiple organ failure was the major cause of mortality in the referred cases and in all these cases, the underlying event was uterine atony, emphasizing the need for active management of labor and prompt management of PPH if it occurs. Such prevention is meaningfully achieved by the use of active management of $3^{\text {rd }}$ stage of labor (oxytocics at anterior shoulder. controlled cord traction, early cord-clamping), which causes reduction in the blood loss, postpartum anemia, need for transfusion and severity of PPH if it occurs. ${ }^{[16]}$

This study also highlights that the mere assessment of mortality data is not enough. Morbidity parameters are more sensitive and efficient. The incidence of morbidity is quite high in our study. A total "near-miss" morbidity incidence of $10.7 \%$ was observed in our study, which is much higher than the reported incidence of $0.05-1.2 \% .{ }^{[11,17,18]}$ Also, comparison reveals that the referred cases had significantly more morbidity. Organ failure, ICU admissions, intubations, blood transfusions and surgical intervention were significantly higher among the referred group. Organ failure and surgical intervention increased sevenfold and 1.2-fold respectively; while ICU admission, extended intubation and transfusion $>3$ units were threefold higher among the referred cases. This reveals that morbidity parameters are much more sensitive and should be incorporated in the clinical reviews to evaluate the actual burden of the problem and find better and effective managemen strategies. Overall, hospital deliveries had a better outcome, milder course and less severity, again implicating substandard care/ delayed care as significant as has been shown by other studies. ${ }^{[19]}$ The significantly less morbidity and "near-miss" cases among the hospital deliveries reflects that the prompt institution of active $3^{\text {rd }}$ stage management in all cases helped to reduce the complications. However, since the sample size is small, it is difficult to compare both mortality and morbidity amongst hospital and non-hospita deliveries.

"Near-miss" morbidity score was started with the intention of evaluation of the existing problem in the developed world, where maternal mortality is on the decline, yet the same can be used to identify the load of significant maternal morbidity in the developing countries since it is a sensitive indicator of pregnancy outcome. ${ }^{[1,17-22]}$ Most studies have implicated hemorrhage as contributing to 24 $64.8 \%$ cases of "near-miss" obstetric morbidity and our study has also shown that the "nearmiss" morbidity assessment is significantly more informative than mortality. ${ }^{[23-26]}$ Therefore, its evaluation along with prediction of risk factors will reduce the disease burden and 
improve health status. Similar conclusions have been also reached with other studies. ${ }^{[11]}$ In conclusion, an assessment of "near-miss" morbidity is as important as mortality data in order to evaluate the actual brunt of the disease in the developing world, where significant morbidity assumes demonic proportions by affecting the quality of life and giving a tsunamic blow to the already staggering economy.

One limitation of this study is that the definition of PPH used is $500 \mathrm{ml}$ blood loss in vaginal deliveries and $1000 \mathrm{ml}$ in cesarean section. This is strictly not in accordance with the WHO definition of PPH, though this is more in agreement with a general observation of blood loss during cesarean section being more than the blood loss during vaginal delivery and also supported by an early study. ${ }^{[4,5]}$ Perhaps a definition that would make allowance for the operative blood loss of a cesarean section and then assess PPH may resolve this issue in future.

\section{REFERENCES}

1. Department of Health. Why mothers die. Report on Confidential Enquiries into Maternal Deaths in the United Kingdom 1994-1996. Dept. of Health (UK): London; 1998.

2. Tuncer RA, Erkaya S, Siphai T, Kutlar I. Maternal mortality in a maternal hospital in Turkey. Acta Obstet Gynecol Scand 1995;74:604-6.

3. al-Meshari A, Chattopadhyay SK, Younes B, Hassonah M. Trends in maternal mortality in Saudi Arabia. Int J Gynecol Obstet 1996;52:25-32.

4. Pritchard JA, Baldwin RM, Dickey JC, Wiggins KM. Blood volume changes in pregnancy and the puerperium II. Red blood cell loss and changes in apparent blood volume during and following vaginal delivery, cesarean section and cesarean section plus total hysterectomy. Am J Obstet Gynecol 1962;84:1271-82.

5. World Health Organization. The prevention and management of post partum haemorrhage. Report of a technical working group. WHO: Geneva; 1990.

6. Amy JJ. Severe postpartum haemorrhage: A rational approach. Natl Med J India 1998;11:86-8.

7. Drife J. Management of primary post partum haemorrhage. Br J Obstet Gynaecol 1997;104:2757.

8. Geller SE, Rosenberg D, Cox SM, Kilpatrick S. Defining a conceptual framework for near-miss maternal morbidity. J Am Med Women Assoc 2002;57:135-9.

9. Geller SE, Rosenberg D, Cox S, Brown M, Simonson L, Kilpatrick S. A scoring system identified near miss maternal morbidity during pregnancy. J Clin Epidemiol 2004;57:716-20.

10. Drife JO. Maternal $\$$ Near-miss $\phi$ reports? BMJ 1993;307:1087-8.

11. Waterstone M, Bewley S, Wolfe C. Incidence and predictors of severe obstetric morbidity: Casecontrol study. BMJ 2001;322:1089-94.

12. Anonymous Report on Confidential Enquiries into Maternal Deaths in the United Kingdom 1991-1993. HMSO: London; 1996.

13. Grimes DA. The morbidity and mortality of pregnancy: Still risky business. Am J Obstet Gynecol 1994;170:1489-94.

14. Berg CJ, Atarsh HK, Koonin LM, Tucker M. Pregnancy related mortality in the United States, 1987-1990. Obstet Gynecol 1996;88:161-7.

15. Kwask BE. Post- partum hemorrhage: Its contribution to maternal mortality. Midwifery 1991;7:64-70.

16. Prendiville WJ, Elbourne D, McDonald S. Active versus expectant management in the third stage of labor (Cochrane review). Cochrane Database Syst Rev 2000;3:CD000007.

17. Fitzpatrick $C$, Halligan $A$, McKenna $P$, Coughlan BM, Darling MR, Phelan D. Near miss maternal mortality (NMM). Ir Med J 1992;85:37.
18. Mantel GD, Buchmann E, Rees H, Pattinson RC. Severe acute maternal morbidity: A pilot study of a definition for a near-miss. Br J Obstet Gynaecol 1998;105:985-90.

19. Combs CA, Murphy EL, Laros RK Jr. Factors associated with post partum hemorrhage with vaginal birth. Obstet Gynecol 1991;77:69-76.

20. Stones W, Lim W, Al-Azzawi F, Kelly M. An investigation of maternal morbidity with identification of life-threatening 'Near miss' episodes. Health Trends 1991;23:13-5.

21. Bewley S, Creighton SB. 'Near-miss' obstetric enquiry. J Obstet Gynaecol 1997;17:26-9.

22. Baskett TF, Sternadel J. Maternal Intensive Care and near miss mortality in Obstetrics. Br J Obstet Gynecol 1998;105:981-4.

23. Brace V, Penney G, Hall M. Quantifying severe maternal morbidity: A Scottish population study. Br J Obstet Gynecol 2004;111:481-4.

24. Rowan K, Golfrad C. Intensive Care National Audit and Research Centre ICNARC. July 2000.

25. Murphy DJ, Charlett P. Cohort study of near-mis maternal mortality and subsequent reproductive outcome. Eur J Obstet Gynecol Reprod Bio 2002;102:173-8.

26. Tang LC, Kwok AC, Wong AY, Lee YY, Sun KO, So AP. Critical care in obstetrical patients: An 8 year review. Chin Med J Eng 1997;110:936-41. 